\title{
An Explanatory Model for Projecting Regional Fertility Differences in the Netherlands
}

\author{
Joop de Beer $\cdot$ Ingeborg Deerenberg
}

Published online: 21 September 2007

(C) Springer Science+Business Media B.V. 2007

\begin{abstract}
Current differences in the level of the total fertility rate (TFR) between Dutch municipalities are smaller than they were in the 1970s and 1980s. Nevertheless, there are still considerable differences. Small municipalities have higher TFRs than large cities. This article aims to answer the question whether these differences will decline further until differences between large and small cities disappear. For that purpose we develop a regression model of regional differences in the TFR including demographic, socioeconomic, and cultural variables. Using the estimation results we decompose differences in fertility between large and small cities into the contribution of differences in levels of the determinants versus differences in the relationships between the determinants and fertility. The results show that differences in cultural variables have a larger effect on differences in the TFR than the demographic and socioeconomic variables. As cultural differences do not tend to change quickly, they will not lead to quick changes in regional differences in the TFR. Demographic differences are not expected to lead to strong changes either, as the two demographic variables (household structure and ethnic structure) have opposite effects. As the effect of the socioeconomic variable is caused by differences in the magnitude of the regression coefficient rather than by differences in the value of this variable, even if differences in this variable disappeared, this would still not lead to convergence of the TFR. Thus the article concludes that differences in the TFR between large and small cities are not likely to diminish quickly.
\end{abstract}

\footnotetext{
J. de Beer $(\bowtie)$

Netherlands Interdisciplinary Demographic Institute, P.O. Box 11650, 2502 AR The Hague, The Netherlands

e-mail: beer@nidi.nl

I. Deerenberg

Statistics Netherlands, P.O. Box 4000, 2270 JM Voorburg, The Netherlands
} 
Keywords Fertility $\cdot$ Regional population projections · TFR

\section{Introduction}

Despite the small size of the Netherlands there are considerable regional differences in fertility rates. Whereas the average value of the Total Fertility Rate (TFR) equals 1.8, the levels of the TFR of the almost 500 municipalities range from 1.3 to 3.2. For making regional population forecasts, assumptions need to be made about the future regional differences in the level of fertility, in addition to assumptions about migration and mortality. These assumptions may be based on projections based on observed differences. However, without having an explanation for the regional differences, it is difficult to decide whether changes observed in the past are likely to continue in the future and, if so, to what extent. In order to assess whether or not differences may be persistent, this article examines which factors explain regional differences in fertility in the Netherlands. The article focuses on differences in the level of TFR between small and large cities.

Three types of explanations are examined. First, differences in the TFR between municipalities may be explained by differences in the demographic structure of the population as well as by socioeconomic and cultural differences. Second, the relationship between these determinants and fertility may differ across municipalities. Third, the level of fertility of municipalities in specific regions may systematically differ from that of municipalities in other regions, apart from the differences that can be attributed to these determinants. The relative importance of each of these three types of explanations is assessed by means of specifying a regression model. The model is estimated on the basis of data that are obtained from Statline, the electronic database of Statistics Netherlands. By means of estimating the model both for all municipalities and for small and large cities separately, the model can be used to decompose differences in fertility between large and small cities into differences in the values of the explanatory variables and differences in the values of the regression coefficients. On the basis of assumptions on possible future changes in the determinants of regional fertility differences we will discuss whether the three types of explanations are likely to lead to a decline of fertility differences between large and small cities or whether differences may be expected to be persistent.

\section{Explanations of Regional Fertility Differences}

Most studies of regional differences in fertility focus on the total fertility rate (TFR). One important reason for using this indicator is that it is not affected by differences in the age and sex structure. One problem in using the TFR as a measure of fertility is that it is affected by changes in the age at childbearing. Hence, for analyzing changes in fertility on the national level an indicator of cohort fertility may be used. However, for an analysis of the level of fertility in small regional areas cohort 
fertility is a less useful measure than at the national level, since a relatively large part of the population moves between different municipalities during the reproductive ages. Thus a cohort fertility indicator for a given municipality does not measure the fertility behavior of "real" cohorts living in that municipality. It would be affected heavily by migration flows in the past. Hence, cohort measures of fertility do not seem to be very useful for analyzing fertility differences between municipalities.

In explaining differences in fertility between regions a distinction can be made between differences in the structure of the population and differences due to different characteristics of the regions (Duchêne et al. 2004). The structure of the population affects the level of fertility because the level of fertility differs between subcategories of the population. For example, fertility rates for married women of ethnic origin aged around 25 are higher than fertility rates for young, native women living alone. Hence, a municipality in which the former group is relatively large and the latter group is relatively small will have a higher TFR than other municipalities. Since the level of the TFR is not affected by the age and sex structure, age and sex do not have to be included in an explanatory model for the TFR. Obviously, other effects of the structure of the population on fertility, such as marital status and ethnicity, might also be accounted for by means of standardizing, but that would require very detailed data on both fertility and the structure of the population, which are usually not available at a low regional level.

Boyle (2003) and Sandberg and Westerberg (2005) note that there are only a few recent studies on regional differences in fertility and that most studies focus on cross-country comparisons. One notable exception is Hank (2001, 2002), who distinguishes two categories of regional characteristics that affect fertility behavior: economic opportunities and constraints on the one hand, and social structure and culture on the other. First, fertility behavior is affected by constraints imposed by the regional living conditions (e.g., Courgeau and Baccaini 1998). Hank (2001) mentions the degree of urbanization (reflecting the "general opportunity of an individual's residence"), the local labor market, the availability of child care, the occupational structure, and regional unemployment. Duchêne et al. (2004) add the housing market. Second, the social environment affects fertility behavior because of regional differences in attitudes toward the family and children.

Most economic studies on fertility refer to the "new home economics" theory of Becker (e.g., Becker 1960, 1991). Becker argues that as raising children costs relatively much time, the costs of children are determined to an important extent by the price of time. Since women tend to spend more time on raising the children than men, the income that a woman could earn if she participated in the labor market has an impact on fertility. Fahey and Spéder (2004) note that when Becker formulated his theory on the economics of fertility, there was a negative relationship between female employment and fertility across OECD countries. However, since the 1980s the relationship has turned the other way around and become strongly positive. Engelhardt et al. (2004) and Del Boca (2002) argue that the change of the sign in the cross-country correlation can be explained by the fact that the "costs" of children do not depend only on the female wage level, but also on institutions determining the ability of women to combine children and work, e.g., opportunities for part-time 
employment and availability of child care. Sandberg and Westerberg (2005) conclude that high labor income in a region may imply good economic conditions, which in turn may encourage young people to start a family. This is in line with the results shown by Hoem (2000) that there is a positive relationship between employment at the municipal level and fertility in Sweden. Sandberg and Westerberg (2005) assume that poor economic conditions are discouraging, hence they expect that high local unemployment has a negative impact on fertility. Kravdal (2002) argues that unemployment does not only affect the level of fertility of those currently unemployed but that high local unemployment rates may depress wages generally. Moreover, high unemployment in the neighborhood strengthens people's doubts about having another child as people may consider the risk of experiencing unemployment in the future as relatively high. Gauthier and Hatzius (1997) state that high unemployment has a discouraging effect on women in permanent jobs, since the risk of not being re-employed on the same terms as before childbirth will be too high. Several empirical studies on regional fertility show a negative relationship between unemployment and fertility: Naz (2000) and Kravdal (2002) for Norway, Johansson (2000) for Sweden and Del Bono (2002) for Great Britain and Italy.

Whereas economic explanations of differences in fertility are based on the assumption that fertility behavior depends on weighing costs and benefits of having children, cultural explanations emphasize the role of values and norms as to the "ideal" family size. In analyzing the decline of fertility to below-replacement levels in many European countries, Lesthaeghe and Van de Kaa introduced the concept of the "second demographic transition" (Lesthaeghe and Van de Kaa 1986; Van de Kaa 1987). They explain the decline of fertility by the rise of values fostering individual autonomy, secularism, postmaterialism, and emancipation in addition to economic factors, such as female labor force participation and housing conditions (Lesthaeghe and Surkyn 2002; Surkyn and Lesthaeghe 2004). The concept of the second demographic transition is based on the assumption that shifts in values are similar across countries: "post-material" values emphasizing individualism are gaining ground at the expense of more conservative values emphasizing duty (Van de Kaa 2001). Coleman (2004) questions, however, whether liberating forces would lead to convergence, as people may not necessarily be liberated in the same direction. Billari and Wilson (2001) show that preferences regarding family formation differ according to cultural context and differences between European countries are stable. Hofstede (1981) claims that cultural differences between countries are very stable through time. There is only a convergence of superficial aspects of culture (e.g., consumption patterns, amusement), but not of the fundamental values. Accordingly, one may expect regional cultural differences within the same country to be persistent. Reher (1998) shows that differences in norms on family size between European countries have been persistent. They have deep historical roots and they are not diminishing in any fundamental way.

From this discussion of the literature we conclude that a model for explaining regional differences in fertility should include demographic variables reflecting differences in the structure of the population, socioeconomic variables reflecting differences in opportunities and constraints, and cultural variables that reflect 
differences in values. The question of to what extent differences in fertility between large and small municipalities are likely to change in the future depends on the question of whether the differences in the determinants are likely to change and on the magnitude of the effect of the separate determinants on fertility differences.

\section{Method}

For making assumptions about future differences in regional fertility it is important to assess which causes of differences in fertility tend to be permanent and which causes may be temporary. First, differences in the TFR are caused by differences in the demographic structure between municipalities, particularly differences in the proportions of women of ethnic origin and of married women in the childbearing ages. These differences may change due to migration. Second, differences in the TFR can be explained by socioeconomic and cultural differences between municipalities. Billari and Wilson (2001) state that whereas economic forces have led to converging trends in Europe, cultural factors have generated diverse family trends. Third, the level of the TFR of municipalities in specific regions may differ from that in other regions, even if differences due to demographic, socioeconomic, and cultural variables are accounted for. By means of examining whether these differences were also observed in the past one may conclude whether these differences are likely to be persistent.

In order to assess the size of the effects of these sources of variation a model is developed in which regional differences in the TFR are explained in two steps. First, an explanatory model is specified which includes variables that reflect demographic, socioeconomic, and cultural differences between municipalities. In the second step, systematic regional patterns in the TFR that cannot be explained by these variables are identified on the basis of an analysis of the residuals of the model specified in the first step, and regional dummy variables are added to the model. In the first step the following model is specified:

$$
\mathrm{TFR}_{i}=b_{0}+\sum_{j} b_{j} x_{i, j}+r_{i}
$$

where $\mathrm{TFR}_{i}$ is the total fertility rate in municipality $i, x_{i, j}$ are the explanatory variables, and $r_{i}$ are regional differences in the TFR that cannot be explained by the variables included in the model, with $\mathrm{E}\left(r_{i}\right)=0$. TFR, $x$, and $r$ refer to year $t$; a subscript indicating the year $t$ is left out for the sake of readability. It can be expected that $r$ exhibits spatial autocorrelation, as municipalities within the same region may show similar differences in fertility that cannot be explained fully by the variables included in model (1). Moran's I coefficient is the most commonly used coefficient in spatial autocorrelation analyses (e.g., Diniz-Filho et al. 2003). If there is spatial autocorrelation (i.e., if Moran's I is close to -1 or +1 ), estimation of the coefficients $b_{0}$ and $b_{j}$ of (1) by OLS would lead to underestimating the standard errors. Moran's I measures the overall pattern of spatial autocorrelation within a given distance class. However, even if the value of Moran's I is close to zero, there still may be systematic patterns in the residuals in some specific regions, which do 
not lead to a high absolute value of Moran's I if there are no systematic patterns in other regions. Therefore it is useful to examine whether there are regions in which the residuals $r_{i}$ indicate that the TFRs of the municipalities within that region are systematically lower or higher than would be expected on the basis of the values of the explanatory variables. These systematic differences can be modeled by:

$$
r_{i}=\Sigma_{k} c_{k} D_{i, k}+\varepsilon_{i},
$$

where $D_{i, k}=1$ if municipality $i$ belongs to region $k$ and $D_{i, k}=0$ otherwise and $\varepsilon_{i}$ is an error term with $\mathrm{E}\left(\varepsilon_{i} \varepsilon_{k}\right)=0$ for $i \neq k$ and $\mathrm{E}\left(\varepsilon_{i}\right)^{2}=\sigma_{\varepsilon}^{2}$. The term $\Sigma_{k} c_{k} D_{i, k}$ describes the systematic regional differences in the TFR that cannot be explained by model (1), whereas the error term describes the random variations. Combining (1) and (2) yields

$$
\mathrm{TFR}_{i}=b_{0}+\sum_{j} b_{j} x_{i, j}+\Sigma_{k} c_{k} D_{i, k}+\varepsilon_{i}
$$

If the error term is serially uncorrelated, the parameters can be estimated by OLS. One benefit of modeling spatial correlation by means of including dummy variables rather than introducing a spatial lag or error model is that the dummy variables allow us to account for differences in the degree of autocorrelation across regions. Even if overall autocorrelation is relatively small, autocorrelation between municipalities in specific regions may be relatively high. Introducing dummy variables for the latter regions provides information on deviations in the TFR that can be attributed to characteristics of specific regions that cannot be accounted for by the demographic, socioeconomic, and cultural variables included in the model.

By means of estimating Eq. 3 both for all municipalities and for large and small cities separately, the regression model can be used to decompose differences in fertility into the effect of differences in the values of the determinants and the effect of differences in the values of the regression coefficients. The contribution of differences in determinants can be calculated by multiplying the estimated values of the regression coefficients in the model estimated for all municipalities by the average values of the explanatory variables in large and small cities respectively and calculating the difference of both products for each explanatory variable. The contribution of the differences in the values of the regression coefficients is calculated by multiplying the average value of the explanatory variables for all cities by the regression coefficients estimated for small and large cities respectively and calculating the differences.

\section{Data}

As discussed in the previous section, for explanatory model (1) three categories of variables are specified. As the data are obtained from Statline, the electronic database of Statistics Netherlands that can be found on http://www.statline.cbs.nl, the choice of variables depends on the availability of data in this database. Statline contains regional data on population, households, labor, income, social security, housing, and elections. 


\section{Demographic Variables}

These variables reflect differences in the household and ethnic structure of the population. As noted in the previous section, changes in the age and sex structure do not have to be included in the model as the TFR is not affected by those changes. It can be expected that the level of the TFR is affected by the household structure, since the level of fertility of couples is considerably higher than that of people living alone. In addition, the level of the TFR is expected to depend on the size of ethnic groups, as women of nonwestern origin tend to have more children than native women. Thus two demographic variables are included in the model:

- Household structure: this variable is measured by the percentage of women aged 20-40 years living alone. This age group is selected because the major part of fertility is realized within this age group.

- Ethnic structure: measured by the percentage of women aged 15-30 years with foreign nonwestern backgrounds, more specifically, women with Turkish or Moroccan backgrounds. The age group is younger than that of the household variable because ethnic women tend to have their children at a younger age than native women. Turks and Moroccans make up two of the largest four ethnic groups in the Netherlands. Because the other two large groups, Surinamese and Antilleans, do not have higher fertility than the average Dutch level, this variable is restricted to Turkish and Moroccan women.

\section{Socioeconomic Variables}

Socioeconomic variables are included in the model in order to reflect the assumption that the level of fertility depends on economic constraints and opportunities. The housing market may have an effect on couples' childbearing decisions. The availability of houses may attract couples from other municipalities, thus leading to selective migration of couples who want to have children. In particular, areas in which relatively many new houses are built tend to attract couples in the family-building stage of life. In addition, the level of fertility is assumed to be related to wealth. As raising children is expensive it is assumed that couples with low incomes and especially couples in which one or both partners do not have jobs, tend to have fewer children than the ideal family size. This assumption corresponds with the empirical finding discussed in the previous section that cross-country studies show a positive relationship between income and the TFR and various regional studies show a negative relationship between unemployment and fertility. Thus it is expected that the TFR is low in municipalities in which a relatively large proportion of the population does not have paid work. Hence, the following variables are included in the model:

- New houses: the number of newly built houses as a percentage of the stock of houses. As it is assumed that young couples first move to their new house and then have children, the percentage of new houses in the 2 years preceding the year for which the TFR is to be explained is included in the model. 
- The percentage of the population with low income. This is measured by the percentage of persons receiving the minimum wage.

- The percentage of the population receiving social benefits, either because of unemployment, disability, or absence of other means of income.

\section{Cultural Variables}

One problem in identifying cultural differences between municipalities is that they are difficult to measure directly. Surveys that include questions on values do not have enough observations for analyses at the level of municipalities. For that reason the impact of cultural influences is assessed indirectly by means of specifying indicators assumed to reflect the effects of cultural differences on fertility. In the Netherlands, as in most other western countries, the effect of religion on the level of fertility nowadays is much smaller than it used to be some decades ago. Nevertheless, there is still some effect, as orthodox Calvinist couples tend to have much higher fertility than the average population (Sobotka and Adigüzel 2002). This leads to relatively high values of the TFR in the so-called Bible Belt, which extends from the southwestern part of the Netherlands in a northeastern direction. In addition, many studies have shown that in rural areas the level of fertility tends to be higher than in urban areas. Norms have a stronger impact in rural areas as social control and direct social influence play a more important role in rural than in urban areas. Because cultural differences tend to be persistent over a long period of time, the effect of unobserved cultural differences on the TFR can be assessed by examining to what extent differences in the TFR have been long-lasting. For that reason, the difference in the TFR between each municipality and the average level some decades ago is included in the model. Hence, the following three variables assumed to represent cultural differences are included in the model:

- Religion: because there are no accurate data for small municipalities of the percentage of the population affiliated with orthodox Calvinist churches, an indirect measure is used, viz. the percentage of persons who voted for orthodox Calvinist parties during the elections of the Dutch Lower House in 2002. Similarly, Brunetta and Rotondi (1989) use election results of the Christian Democrats as an indicator of the importance of Catholic culture in a province.

- Urbanization rate: the degree of urbanization is measured by the number of addresses per square kilometer. Five classes of urbanization rate are distinguished ranging from very low urbanization rate (fewer than 500 addresses per $\mathrm{km}^{2}$ ) to very high urbanization rate (more than 2,500 addresses per $\mathrm{km}^{2}$ ). Four dummy variables are included in the model representing the levels of urbanization, ranging from very low to high urbanization rates.

- Non-specified cultural differences: differences of the TFR from the average level in 1969 are regarded as a proxy for long-lasting differences in fertility. In the Netherlands the TFR changed dramatically in the years 1969-1975. On the national level the TFR dropped from 2.75 in 1969 to 1.66 in 1975. One major cause of this fall was the strong decline in the age at childbearing. Because the 
change in the timing of fertility also affected the level of the TFR in subsequent years, it was decided to include the TFR in the last year preceding this unstable period in the model rather than the TFR in 1975. Thus the difference between the TFR of each municipality in 1969 and the average level is included in the model.

On the basis of the expected signs of the regression coefficients, it is assumed that the TFR is high in municipalities where a high percentage of women is living with a partner, a high percentage of women in the reproductive ages has a nonwestern background, the percentage of new houses is high, there are low percentages of persons with low incomes and persons receiving social benefits, a high percentage of the population belongs to the orthodox Calvinists, the urbanization rate is low, and the level of fertility has been high in the past.

An analysis of the residuals of model (1) shows to what extent there are systematic regional patterns that cannot be accounted for by the explanatory variables included in the model. On the basis of the classification developed by Eurostat, three levels of regional aggregations of municipalities are examined:

(a) NUTS I level. The Netherlands is divided into four parts: North (consisting of 68 municipalities), East (103 municipalities), West (207 municipalities), and South (118 municipalities). These regions are separated by geographical boundaries.

(b) NUTS II level. The Netherlands consists of 12 provinces. These regions have political boundaries. The number of municipalities per province ranges from 6 to 92.

(c) NUTS III level. Forty so-called COROP regions are distinguished. These are socioeconomic regions. Each region is part of one province. The number of municipalities per COROP region ranges from 2 to 33 .

After assessing in which regions there are systematic differences in the TFR of the municipalities belonging to that region that cannot be accounted for by the explanatory variables, dummy variables for model (2) are specified. In order to limit the number of variables in the model, a hierarchical procedure is followed, i.e., first it is determined whether there are significant deviations at the NUTS I level, then at the NUTS II level, and finally at the NUTS III level.

The analyses are based on data for all 496 municipalities of the Netherlands (this was the number of municipalities on 1 January 2002). Population size of the municipalities ranges from 1,000 inhabitants to over 700,000 inhabitants. The model is estimated on the basis of data for the year 2002. As the TFR for many small municipalities shows relatively large random fluctuations from one year to the other, it was decided to calculate the average value of the TFR for three successive years (2000, 2001, and 2002). Whereas for almost $60 \%$ of the municipalities the TFR ranges from 1.6 to $2.0,15 \%$ of municipalities have a level of the TFR above replacement level (2.1), and 6\% have a TFR lower than 1.5. The (unweighed) average value of the TFR equals 1.8, and the standard deviation equals .26. The TFR is low (1.6 on average) in both of the most southern and most northern provinces, which are characterized by rather poor economic conditions, and in the urbanized 
Table 1 Descriptive sample statistics

\begin{tabular}{|c|c|c|c|c|c|c|}
\hline & \multicolumn{2}{|c|}{$<25,000$ Inhabitants } & \multicolumn{2}{|c|}{$>25,000$ Inhabitants } & \multicolumn{2}{|c|}{ All municipalities } \\
\hline & Mean & SD & Mean & $\mathrm{SD}$ & Mean & SD \\
\hline TFR & 1.88 & .23 & 1.78 & .19 & 1.84 & .22 \\
\hline$\%$ Women living alone & 7.21 & 3.10 & 11.63 & 6.92 & 8.83 & 5.31 \\
\hline$\%$ Moroccan and Turkish women & 1.31 & 2.01 & 4.53 & 4.14 & 2.49 & 3.35 \\
\hline$\%$ New houses & 4.51 & 3.43 & 5.50 & 4.71 & 4.87 & 3.97 \\
\hline$\%$ Persons with low income & 7.17 & 1.86 & 8.27 & 2.38 & 7.58 & 2.13 \\
\hline$\%$ Persons receiving social benefits & 11.96 & 3.15 & 14.58 & 3.37 & 12.92 & 3.47 \\
\hline$\%$ Orthodox Calvinists & 5.26 & 8.21 & 4.38 & 5.52 & 4.94 & 7.34 \\
\hline Very low urbanization (dummy) ${ }^{\mathrm{a}}$ & .47 & & .10 & & .33 & \\
\hline TFR in the past (deviation from average) & .12 & .60 & -.21 & .42 & 0.00 & .56 \\
\hline$N$ & 314 & & 182 & & 496 & \\
\hline
\end{tabular}

a Standard deviation is not given, as this is a binary variable

Source: Statline (http://www.cbs.nl)

western provinces (1.7). The TFR is high in the new province of Flevoland (2.0) and also in the rural eastern provinces (1.9). A large part of Flevoland was reclaimed from the IJsselmeer lake. It consists of three polders, the last of which was created in the 1960s. Its biggest city, Almere, received its first inhabitants in 1976. Now it has 170,000 inhabitants.

Table 1 shows the mean values and standard deviations of the TFR and the explanatory variables, separately for small and large municipalities. The table shows that the TFR is higher in small municipalities than in larger ones. On the basis of the hypotheses on the signs of the coefficients discussed above it can be assumed that the relatively high level of the TFR in small municipalities can be explained by the relatively low percentage of women living alone, the high percentage of orthodox Calvinists and the high level of fertility in the past. However, these effects are counterbalanced by the low percentage of people with nonwestern foreign backgrounds, the low percentage of new houses, and the low percentage of persons receiving social benefits. Thus a multivariate analysis is needed to quantify the size of these different effects on the fertility differences.

\section{Results}

Most regression coefficients of the explanatory variables turn out to differ significantly from zero and have the expected sign. The regression coefficient of the income variable does not differ significantly from zero, hence this variable is not included in the model. Furthermore, three of the four dummies representing different degrees of urbanization do not differ significantly from zero. Thus only the coefficient of the dummy representing very low urbanization is included in the model. Moran's I is calculated by estimating the spatial autocorrelation of the values 
of the TFRs and the residuals of municipalities within the same regions at the NUTS III level. Moran's I of the TFR equals .24 and that of the residuals of the model including the demographic, socioeconomic, and cultural variables equals .14. Thus there is no strong spatial autocorrelation. However, for two regions at the NUTS II and six at the NUTS III level the residuals turn out to be systematically positive or negative. For that reason eight regional dummies are added to the model. After including the regional dummies, Moran's I equals .05, indicating that there is no autocorrelation left in the residuals. In five regions the TFR is higher than would be expected on the basis of the demographic, socioeconomic, and cultural explanatory variables, whereas three regions turn out to have relatively low TFRs. The TFR is especially high in the fairly new province of Flevoland. This province attracts many young couples who move from Amsterdam, as this province provides many dwellings with gardens that are considered to be attractive for rearing children. Moreover, this province includes one "old" municipality belonging to the Bible Belt, Urk, with very high fertility that cannot be completely accounted for by the explanatory variables (we will come back to this later).

The model is estimated separately for the 182 municipalities with 25,000 and more inhabitants and the 314 municipalities with less than 25,000 inhabitants. Table 2 shows the estimated regression coefficients, their standard errors and the $t$ statistics. The model turns out to explain $78 \%$ of the variance of the TFR for the large municipalities and $61 \%$ of that for small municipalities. Taking all municipalities together the model explains $67 \%$ of the variance. The main part of the explained variance can be attributed to the demographic, cultural, and socioeconomic explanatory variables. These variables explain $62 \%$ of the variance of the TFR for all municipalities.

By means of combining information from Table 1 on the mean values of the explanatory variables and the values of the regression coefficients shown in Table 2 one can explain the higher value of the TFR in the small cities. In cities with fewer than 25,000 inhabitants the average value of the TFR equals 1.88 and in the larger cities the TFR equals 1.78. This difference can be decomposed into the contribution of differences in the values of the explanatory variables between large and small cities versus differences in the values of the regression coefficients. The contribution of both differences is shown in Table 3 .

Looking at the differences in the explanatory variables between small and large cities it turns out that the two demographic variables have opposite effects. The percentage of women living alone accounts for a difference in the TFR of .06. This can be calculated as follows. In small municipalities $7.2 \%$ of women aged between 20 and 40 years live alone compared with $11.6 \%$ in large cities (see Table 1). As the regression coefficient of this variable in the model estimated for all municipalities equals -.013 , this variable accounts for a difference of $-.013 \times(7.2-11.6)=.06$ in the TFR between small and large cities. The percentage of ethnic women has an opposite effect. As the percentage of women with Turkish or Moroccan backgrounds is lower in small cities than in large cities, whereas this variable has a positive effect on the level of the TFR, this variable has a downward effect on the TFR for small cities. The size of this effect on the difference between small and large municipalities equals -.03 . Thus taken together, the two demographic 
Table 2 Estimation results on the determinants of the TFR

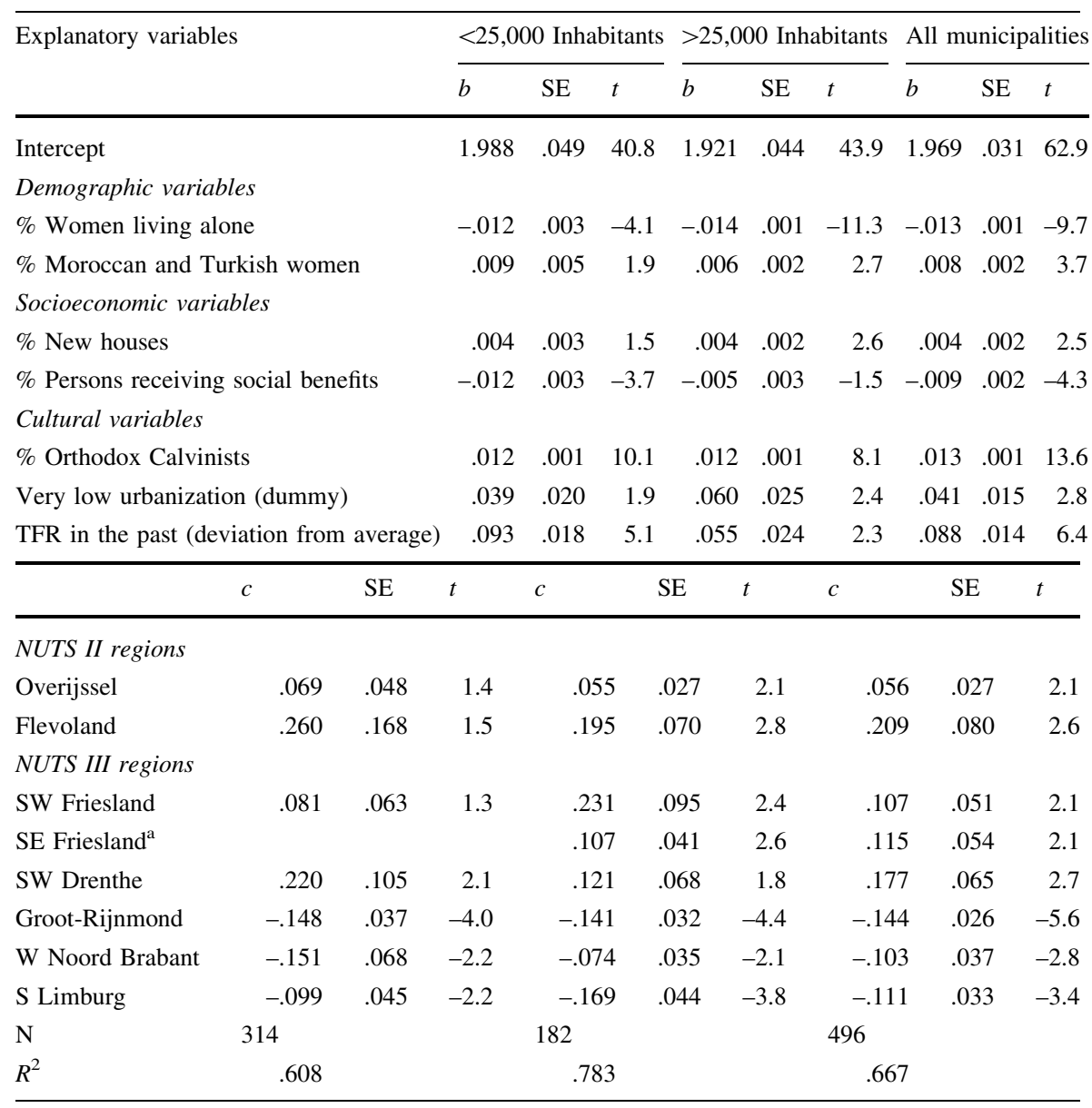

a No coefficient for small municipalities is shown because there are no small municipalities in this region

variables explain .03 of the total difference in the TFR. Similarly, the effects of the different values of the cultural and socioeconomic variables can be calculated. The two socioeconomic variables explain a difference in the TFR of .02 (.00 by new houses and .02 by persons receiving social benefits) and the three variables representing cultural differences explain a difference of .06 of the TFR (.01 by religion, .02 by urbanization, and .03 by past differences in the TFR).

As to the differences in the estimated values of the regression coefficients, the main difference between small and large cities concerns the percentage of persons receiving social benefits. The percentage of people receiving social benefits is higher in large cities than in small cities. As the regression coefficient is negative, this seems to partly explain the lower fertility in large cities. However, this effect is offset by the fact that the (absolute) value of the coefficient is larger in small cities than in large cities. Thus, even though in small cities the percentage of people 
Table 3 Difference in TFR between small and large cities

\begin{tabular}{|c|c|c|c|}
\hline & $\begin{array}{l}\text { Contribution of differences } \\
\text { in mean values of } \\
\text { explanatory variables }\end{array}$ & $\begin{array}{l}\text { Contribution of } \mathrm{d} \\
\text { ifferences in } \\
\text { regression coefficients }\end{array}$ & $\begin{array}{l}\text { Total contribution to } \\
\text { difference in TFR } \\
\text { between small and } \\
\text { large cities }\end{array}$ \\
\hline \multicolumn{4}{|l|}{ Demographic variables } \\
\hline$\%$ Women living alone & .06 & .02 & .08 \\
\hline $\begin{array}{l}\% \text { Moroccan and } \\
\text { Turkish women }\end{array}$ & -.03 & .01 & -.02 \\
\hline Total effect & .03 & .03 & .06 \\
\hline \multicolumn{4}{|l|}{ Socioeconomic variables } \\
\hline$\%$ New houses & .00 & .00 & .00 \\
\hline $\begin{array}{l}\% \text { Persons receiving } \\
\text { social benefits }\end{array}$ & .02 & -.09 & -.07 \\
\hline Total effect & .02 & -.09 & -.07 \\
\hline \multicolumn{4}{|l|}{ Cultural variables } \\
\hline$\%$ Orthodox Calvinists & .01 & .00 & .01 \\
\hline $\begin{array}{l}\text { Very low urbanization } \\
\text { (dummy) }\end{array}$ & .02 & -.01 & .01 \\
\hline $\begin{array}{l}\text { TFR in the past } \\
\text { (deviation from average) }\end{array}$ & .03 & .00 & .03 \\
\hline Total effect & .06 & -.01 & .05 \\
\hline Intercept & .00 & .07 & .07 \\
\hline Total & .11 & -.01 & .10 \\
\hline
\end{tabular}

receiving social benefits is lower than in large cities, this variable has a larger impact on the TFR in small cities. Thus in small cities with many people receiving social benefits the TFR is relatively low compared with other small cities. As to the difference between small and large cities, the large (absolute) value of the coefficient in small cities implies that this variable has a negative impact on the level of the TFR in small cities. This negative effect exceeds the positive effect due to the lower percentage of persons receiving social benefits in small cities. The opposite is true for the percentage of women living alone. Because the (absolute) value of the regression coefficient is higher for large cities this enlarges the effect of the higher percentage of women living alone in large cities. The difference in the values of the intercept for small and large cities implies that part of the difference in the TFR cannot be accounted for by the explanatory variables. The different values of the regression coefficients of the regional dummies indicate that in four regions the difference in the TFR between small and large municipalities is larger than the difference in the intercept indicates.

If we take both effects together, it turns out that the .10 difference in the TFR between large and small municipalities is made up of a difference of .06 that can be explained by the demographic variables, .05 by the cultural variables, and .07 by not-specified differences (accounted for by differences in the intercept between large and small cities), whereas the socioeconomic variables have an opposite effect of .07 . 
In all eight regions included in the model the TFR in the past already differed in the same direction as the signs of the regression coefficients indicate. These differences are not completely explained by the variable TFR in the past. This indicates that the reduction of the TFR during the last decades has not been similar in all regions. For all municipalities taken together the model implies that current differences in the TFR equal less than $10 \%$ of the differences in 1969 (the regression coefficient equals .087, see Table 2). However, for the eight regions included in the model the current differences in the TFR are about one half of the past differences. This indicates that in those regions the difference of the TFR with the national average has declined much more slowly than in other regions.

\section{Implications for Forecasting}

In the previous section we showed to what extent the difference of the TFR between large and small municipalities can be explained by differences in the values of demographic, socioeconomic, and cultural variables and by differences in the magnitude of the regression coefficients. On the basis of assumptions on the possible future direction of change in differences in these variables one may conclude to what extent future differences in the TFR are expected to decline or to be persistent.

Future changes in the demographic structure depend on the current age and sex structure and on future changes in migration and household formation (changes in mortality hardly play a role in explaining changes in the number of women in the childbearing ages and changes in fertility have an effect in the long run only). As to changes in socioeconomic regional differences, Cuadrado-Roura (2001) shows that after a period of regional economic convergence in the European Union, this process has almost completely ended. Fingleton (1999) claims that there is only weak evidence that EU regions are converging, requiring more than two centuries for economic convergence to be achieved. As to cultural differences, Lesthaeghe and Neels (2002) suggest on the basis of an analysis of spatial differences in fertility that are linked to cultural variables between regions in Belgium, France, and Switzerland that these are rather stable across time.

The demographic variables lead to a lower TFR in large municipalities due to the higher percentage of single women. Thus if the difference in this percentage between municipalities becomes smaller this will lead to smaller differences in the TFR. However, the other demographic variable (viz. ethnicity) has an opposite effect. Since this variable has an upward effect on the level of the TFR, convergence of the percentage of foreign women (due to a stronger increase of this percentage in small municipalities than in large municipalities) would lead to diverging trends in the level of the TFR. As the coefficient of the household variable exceeds that of the ethnicity variable one may expect that the former effect will be larger than the latter (assuming that the change in the percentage of ethnic women is not considerably larger than the change in the percentage of women living alone). Consequently if demographic differences between large and small cities would become smaller, this can be expected to lead to some convergence in the TFR, although the total effect 
will be only moderate due to the effects in opposing directions. However, one may question whether it is likely that demographic differences between small and large cities will become smaller. Selective migration may cause differences in the population structure to be persistent. If couples wanting to raise a family move to non-urban regions whereas singles move to large cities, the differences in the household structure between large and small cities may not tend to decline. Similarly, if new immigrants move to cities where many ethnic groups are already living, the differences in the ethnic structure may not become smaller either. Furthermore, one may expect the level of fertility of ethnic groups to decline in the future due to the integration of ethnic groups in society. This would lead to a lower value of the regression coefficient of the ethnic variable. Consequently the TFR in large cities would decline, causing a bigger difference in the TFR between large and small cities. Summing up, it can be concluded that demographic changes are not expected to lead to smaller differences in the TFR between large and small cities.

The main effect of the socioeconomic variables is that of the percentage of people receiving social benefits. In the previous section it was shown that the effect of this variable on the difference in the TFR between small and large cities is not so much caused by differences in the value of this explanatory variable but rather by the difference in the size of the effect (i.e., the value of the regression coefficient). This is due to the fact that this variable has a larger impact on the TFR of small municipalities than that of large ones. This implies that if the difference in the percentage of people receiving social benefits between small and large cities would reduce and the value of the regression coefficient would not change, this would have only moderate effect on the difference in TFR.

The three cultural variables have effects in the same direction. However, as cultural differences do not tend to change quickly, they may not lead to a strong convergence of the TFR in the near future. But in the long run one might expect this variable to lead to some convergence of the TFR. For example, if the percentage of orthodox Calvinists in a small municipality drops by $10 \%$, the TFR is expected to decrease by .12. In addition, the effect of the level of the TFR in the past may lead to a decrease in future differences in the TFR as there has been some convergence in the TFR during the past decades. In 1969 the TFR in small cities was .3 higher than in large cities, whereas around 2000 the difference was .1. However, according to the model the effect of this decrease on the future difference of the TFR between small and large cities will only be moderate, since the regression coefficient is relatively small. For the next 30 years the effect of the past decrease in the difference in the TFR will be a reduction of the average TFR for small cities by .02 .

Finally, the model includes a number of parameters that take account of other effects than those of the explanatory variables. First, the intercept differs between small and large cities. This implies that the relatively high fertility in small cities cannot be completely explained by the demographic, socioeconomic, and cultural variables. In the absence of a clear explanation it is obviously difficult to argue whether a future reduction of this difference can be expected. True, as remarked above, in the last decades we have seen a reduction of the difference in the TFR, but that does not necessarily imply that a further reduction should be expected. Note that the effect of the past reduction in the TFR on the future level is already 
accounted for as the differences of the TFR in the past are included in the model as explanatory variable. Moreover, as Sobotka and Adigüzel (2002) show, regional variation in the TFR declined in the 1970s and 1980s, but has hardly changed in the 1990s. Second, the model includes regional dummies indicating that three regions have lower fertility and five regions have higher fertility than would be expected on the basis of the values of the explanatory variables. As discussed in the previous section, the difference of the TFR in these regions with the national average has declined considerably more slowly than in other regions. This suggests that these differences may be rather persistent, even though the size of the differences has diminished during the last decades.

Summing up these arguments it can be concluded that even though some convergence of the TFR may be expected, it seems likely that it will be only slowly and moderately, and therefore differences in the TFR between large and small cities are likely to be rather persistent.

\section{Conclusions}

Even though there are considerable differences in the levels of the TFR between Dutch municipalities, current differences are smaller than they were in the 1970s and 1980s. This article is aimed to answer the question whether differences will decline further until convergence will be reached or whether differences between municipalities may be expected to be persistent. In order to answer this question we developed a model explaining differences in the TFR between municipalities. The model includes demographic, socioeconomic, and cultural explanatory variables. The demographic variables reflect the effect of differences in the structure of the population on the level of the TFR, the socioeconomic variables reflect differences in opportunities and constraints, and the cultural variables reflect the effect of differences in values. Since these variables are not capable of explaining all systematic regional variations in the TFR, regional dummies are added to the model. In two of the 12 regions at the NUTS II level, fertility turns out to be higher than would be expected on the basis of the values of the explanatory variables for the municipalities in those regions; moreover, in three of the 40 regions at the NUTS III level, fertility is relatively high, whereas in another three regions fertility is low.

The model explains two thirds of the variance of the TFR in the almost 500 municipalities of the Netherlands. Differences in the TFR between large and small cities can be attributed both to differences in the determinants and to differences in the relationship between the determinants and fertility. In order to assess the size of these differences, the model is estimated separately for small and large municipalities. In small municipalities the TFR is .1 higher than in large municipalities. Looking at the difference that can be explained by differences in the values of the explanatory variables the two demographic variables (household structure and ethnic structure) turn out to have opposite effects. The differences in the cultural variables turn out to have a larger effect than the other two types of variables. As to the differences in the regression coefficients, the main difference between small and large cities concerns a socioeconomic variable. The percentage of the population 
receiving social benefits has a much larger impact in small cities than in larger ones. If we take both types of differences together, it turns out that the .10 differences in the TFR between large and small municipalities is made up of a difference by .06 that can be explained by the demographic variables, .05 by the cultural variables, and .07 by not-specified differences, whereas the socioeconomic variables have an opposite effect of .07. In all eight regions included in the model the TFR in the past already differed in the same direction. In those regions the difference of the TFR with the national average has declined much more slowly than in other regions.

Since the two demographic variables included in the model have opposite effects on the difference in the TFR between small and large municipalities, even if the demographic variables would converge, this would not lead to a complete convergence of the TFR. Moreover, due to selective migration one may question whether strong convergence of the demographic variables is likely. Thus demographic trends cannot be expected to lead to strong convergence of the TFR. The effect of the main socioeconomic variable is not so much caused by differences in the value of the explanatory variable but rather by the difference in the size of the regression coefficient. If the difference in the value of this variable between small and large cities would reduce and the value of the regression coefficient would not change, this would have only moderate effect on the difference in TFR. As cultural differences do not tend to change quickly, they may not lead to a strong convergence of the TFR in the near future either, but in the long run one might expect this variable to lead to some convergence of the TFR. In addition, one should take into account the differences in the TFR that cannot be explained by the selected variables. As in the three regions with relatively low fertility and the five regions with relatively high fertility, the difference of the TFR with the national average has declined considerably less than in other regions, these differences may be assumed to be rather persistent in the future. In conclusion, even though some convergence of the TFR may be expected, it is not likely to be quick and strong and thus differences in the TFR between small and large cities may be expected to be rather persistent.

\section{References}

Becker, G. (1960). An economic analysis of fertility. In Demographic and economic change in developed countries (pp. 209-231). Princeton NJ: Princeton University Press.

Becker, G. (1991). A treatise on the family. Cambridge MA: Harvard University Press.

Billari, F., \& Wilson, C. (2001). Convergence towards diversity? Cohort dynamics in the transition to adulthood in contemporary Western Europe. Working Paper 2001-039, Rostock, Germany: Max Planck Institute for Demographic Research.

Boyle, P. (2003). Population geography: Does geography matter in fertility research? Progress in Human Geography, 27(5), 615-626.

Brunetta, G., \& Rotondi, G. (1989). Différenciation régionale de la fécondité italienne depuis 1950. Espace, Populations, Sociétés, 2, 271-291.

Coleman, D. (2004). Why we don't have to believe without doubting in the "Second Demographic Transition"-Some agnostic comments. Vienna Yearbook of Population Research, 11-24.

Courgeau, C., \& Baccaini, B. (1998). Multilevel analysis in the social sciences. Population, 10, 39-71 (English selection).

Cuadrado-Roura, J. R. (2001). Regional convergence in the European Union: From hypothesis to the actual trends. The Annals of Regional Science, 35(3), 333-356. 
Del Boca, D. (2002). The effect of child care and part time opportunities on participation and fertility decisions in Italy. Journal of Population Economics, 15, 549-573.

Del Bono, E. (2002). Total fertility rates and female labor force participation in Great Britain and Italy: Estimation of a reduced form model using regional panel data. Paper presented at the ESPE 2002 conference, 12-15 June 2002, Bilbao, Spain.

Diniz-Filho, J., Bini, L., \& Hawkins, B. (2003). Spatial autocorrelation and red herrings in geographical ecology. Global Ecology and Biogeography, 12, 53-64.

Duchêne, J., Gabadinho, A., Willems, M., \& Wanner, P. (2004). Study of low fertility in the regions of the European Union: Places, periods and causes. Eurostat: Population and social conditions 3/2004/ F/no.4.

Engelhardt, H., Kögel, T., \& Prskawetz, A. (2004). Fertility and female employment reconsidered: A macro-level time series analysis for developed countries, 1960-2000. Population Studies, 58(1), 109-120.

Fahey, T., \& Spéder, Z. (2004). Fertility and family issues in an enlarged Europe. European Foundation for the Improvement of Living and Working Conditions. Retrieved from http://www.euro found.eu.int

Fingleton, B. (1999). Estimates of time to economic convergence: An analysis of regions of the European Union. International Regional Science Review, 22(1), 5-34.

Gauthier, A. H., \& Hatzius, J. (1997). Family benefits and fertility: An econometric analysis. Population Studies, 51, 295-306.

Hank, K. (2001). Regional fertility differences in Western Germany: An overview of the literature and recent descriptive findings. International Journal of Population Geography, 7, 243-257.

Hank, K. (2002). Regional social contexts and individual fertility decisions: A multilevel analysis of first and second births in Western Germany. European Journal of Population, 18, 281-299.

Hoem, B. (2000). Entry into motherhood in Sweden: The influence of economic factors on the rise and fall in fertility, 1986-1997. Demographic Research, 2(4).

Hofstede, G. (1981). Culture's consequences: International differences in work-related values. Beverly Hills CA: Sage Publications.

Johansson, M. (2000). Population and regional development - the case of Sweden. Paper presented at the 40th ERSA Congress, Barcelona, 29 August 29-1 September, 2000.

Kravdal, O. (2002). The impact of individual and aggregate unemployment on fertility in Norway. Demographic Research, 6(10), 261-293.

Lesthaeghe, R., \& van de Kaa, D. (1986). Twee demografische transities? In R. Lesthaeghe \& D. van de Kaa (Eds.), Bevolking: Groei en krimp? (pp. 9-24). Deventer, Netherlands: Van Loghum-Slaterus.

Lesthaeghe, R., \& Neels, K. (2002). From the first to the second demographic transition: An interpretation of the spatial continuity of demographic innovation in France, Belgium, and Switzerland. European Journal of Population, 18, 325-360.

Lesthaeghe, R., \& Surkyn, J. (2002). New forms of household formation in central and eastern Europe: Are they related to newly emerging value orientations? Economic Survey of Europe, 1, 197-216.

Naz, G. (2000). Determinants of fertility in Norway. Working Papers in Economics, Bergen University, Norway.

Reher, D. S. (1998). Family ties in western Europe: Persistent contrasts. Population and Development Review, 24, 203-234.

Sandberg, K., \& Westerberg, T. (2005). Spatial dependence and the determinants of child births in Swedish municipalities 1974-2002. Paper presented at the Spatial Econometrics Workshop, Kiel, Germany, 8-9 April 2005.

Sobotka, T., \& Adigüzel, F. (2002). Religiosity and spatial demographic differences in the Netherlands. SOM Research Report 02F65, University of Groningen.

Surkyn, J., \& Lesthaeghe, R. (2004). Value orientations and the second demographic transition (SDT) in Northern, Western and Southern Europe: An update. Demographic Research, Special Collection, 3, 43-86.

Van de Kaa, D. (1987). Europe's second demographic transition. Population Bulletin, 42(1), 1-59.

Van de Kaa, D. (2001). Postmodern fertility preferences: From changing value orientation to new behavior. Population and Development Review, 27, 290-331. 